\title{
AVALIAÇÃO DA GESTÃO AMBIENTAL EM PEQUENAS PROPRIEDADES PRODUTORAS DE LEITE NO VALE DO TAQUARI A PARTIR DO USO DA MATRIZ IMPORTÂNCIA $X$ DESEMPENHO
}

\section{ASSESSMENT OF ENVIRONMENTAL MANAGEMENT OF MILK PRODUCERS IN SAMLL FARMS IN TAQUARI VALLEY (BRAZIL) USING PERFORMANCE X IMPORTANCE MATRICES}

\author{
Carlos Candido da Silva Cyrne \\ Centro Universitário Univates - Lajeado - RS - Brasil \\ Claudete Rempel \\ Centro Universitário Univates - Lajeado - RS - Brasil \\ Claus Haetinger \\ Centro Universitário Univates - Lajeado - RS - Brasil \\ Rafael Rodrigo Eckhardt \\ Centro Universitário Univates - Lajeado - RS - Brasil
}

Resumo: Estima-se que $12,5 \%$ da produção de leite (um milhão de litros por dia) do Rio Grande do Sul - RS seja oriunda da região denominada Vale do Taquari, envolvendo cerca de nove mil famílias que encontram, nesta atividade, condições de se manter no meio rural. Este trabalho tem por objetivo contribuir com a gestão dessas propriedades, centrando as atenções nos aspectos ambientais e avaliando a matriz "Importância x Desempenho". A área de estudo é constituída por quatro propriedades leiteiras do Município de Arroio do Meio-RS. De posse dos dados da pesquisa realizada por Rempel et al (2012) para avaliação da sustentabilidade ambiental, foi possível verificar a aplicabilidade da matriz "Importância x Desempenho" como ferramenta para priorização de ações de melhoria da qualidade ambiental dessas propriedades. Constatou-se que a matriz aplicada pode ser útil no processo de gestão ambiental das propriedades produtoras de leite no Município de Arroio do Meio, sendo, também, 
possível a aplicação desta metodologia em demais propriedades para avaliação das principais ações a serem desenvolvidas para melhoria da sustentabilidade ambiental. Palavras-chave: Ciências Ambientais. Interdisciplinar. Gestão Ambiental. Produção de Leite.

Abstract: It is estimated that $12.5 \%$ of milk production (one million liters per day) of brazilian Rio Grande do Sul state is coming from the region named Taquari Valley, involving nearly 9,000 families, who find in this activity conditions to remain in rural areas. This work aims to contribute to the management of these properties, by focusing on environmental aspects, evaluating the matrix "Importance x Performance". The study area consists of four small farms in the municipality of Arroio do Meio - RS. Based on the data of a research previously conducted by Rempel et al (2012) to assess the environmental sustainability, it was possible to verify the applicability of the matrix as a tool for prioritizing actions to improve the environmental quality of these properties. It was found that the matrix applied can be helpful in the process of environmental management of the milk producers farms of Arroio do Meio, being also possible to apply this methodology in other properties for assessing key actions to be taken to improve the environmental sustainability.

Keywords: Environmental Sciences. Interdisciplinary. Environmental Management. Milk production.

\section{INTRODUÇÃO}

O ambiente econômico encontra-se em constante evolução, provocando a transformação dos negócios em todos os seus âmbitos. Especificamente, na área da produção de leite, desde o início dos anos 1990, as alterações foram significativas, saindo de um controle estatal sobre os preços, que vigorava desde a década de 1950, para uma liberação dos mesmos. A partir disso houve a necessidade de pensar novamente a cadeia de produção, criando um novo perfil para o setor. Souza (2011, p.49) confirma isso quando afirma que "a reorganização do setor leiteiro é movida pela exigência de um mercado competitivo".

Passou a ser necessário um controle mais intenso e pormenorizado das atividades, sendo maiores as exigências em função da escala de produção, bem como da adoção de novas regras referentes à qualidade do produto e dos processos e a adoção de novos padrões tecnológicos e de gestão, o que nem sempre é acompanhado, principalmente, pelos pequenos produtores.

Segundo dados do Instituto Brasileiro de Geografia e Estatística IBGE (2011), o Brasil tem apresentado um crescimento contínuo na produção de leite no período compreendido entre os anos de 1990 a 
2009, sendo a Região Sul do Brasil uma das mais importantes contribuintes para o referido crescimento uma vez que teve um avanço maior do que o ocorrido na Região Sudeste no mesmo período.

Este trabalho foca em propriedades produtoras de leite no Vale do Taquari-RS, mais precisamente, no Município de Arroio do Meio, tendo em vista a expressiva contribuição econômica e social que a atividade leiteira representa. Com base no Plano de Implantação - Política Industrial Desenvolvimento Econômico do Rio Grande do Sul - 20102013, e nos dados publicados pelo Instituto Brasileiro de Geografia e Estatística - IBGE, é possível constatar que no Estado do RS existem mais de 120 mil estabelecimentos familiares envolvidos com a produção de leite, sendo a atividade presente em mais de $90 \%$ dos municípios gaúchos.

Segundo dados do IBGE (2011), o Estado do RS coloca-se como o segundo maior produtor nacional de leite, abaixo de Minas Gerais e antes do Paraná, com uma produção anual de quatro bilhões litros, respondendo por $12 \%$ da produção nacional. Em termos de valores, o setor movimenta algo próximo a 6 bilhões de reais.

No Vale do Taquari, estima-se que sejam produzidos cerca de um milhão de litros de leite por dia, correspondendo a $12,5 \%$ da produção do estado e envolve cerca de nove mil famílias, sendo o leite, segundo Silva Neto e Basso (2005), uma atividade que apresenta a capacidade de manter a população no meio rural, o que potencializa os seus efeitos sobre as economias locais. Números como esses justificam a atenção que deve ser dispensada ao setor.

$\mathrm{Na}$ Figura 1, pode-se observar as regiões do estado com os índices de produção, litros/vaca/ano, e neste item, a região do Vale do Taquari, representada pela microrregião Lajeado-Estrela, apresenta uma queda quando comparados os anos de 1990 e 2009, mas, ainda, continua tendo uma participação importante. 
Figura 1. Microrregiões do Rio Grande do Sul com maior produtividade

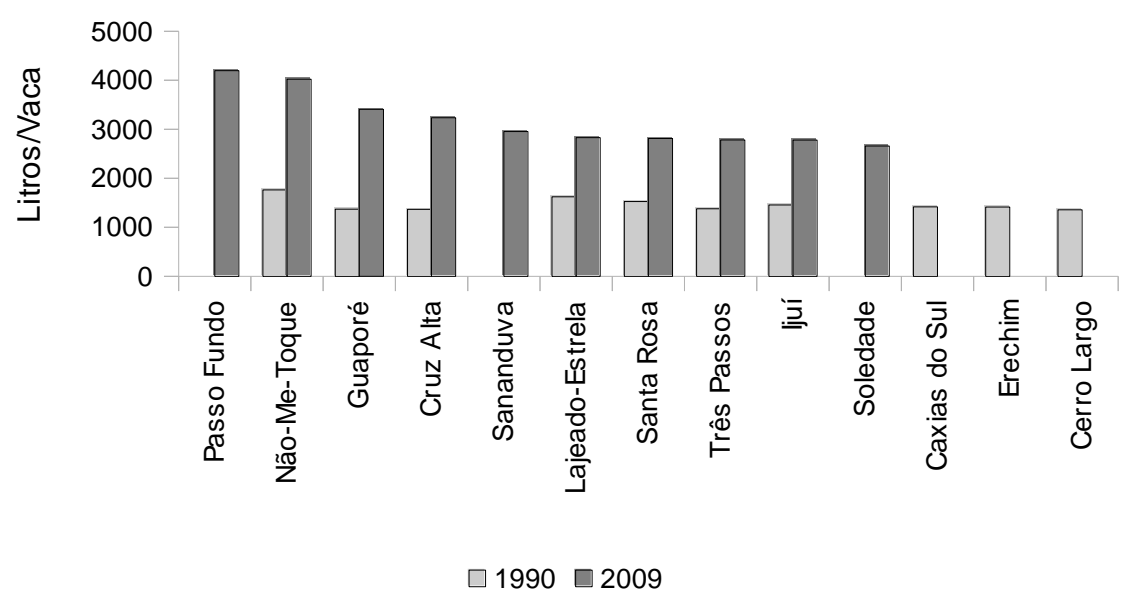

de leite entre 1990 - 2009

Fonte: Marion Filho; Fagundes; Schumacher - 2011.

Para que se possa manter e ampliar a competitividade do setor, é preciso avançar em diferentes aspectos. Este artigo busca abordar a gestão das propriedades centrando atenção nos aspectos ambientais e dá continuidade à pesquisa desenvolvida por Rempel et al (2012) que buscou definir uma proposta metodológica para a avaliação da sustentabilidade ambiental de propriedades produtoras de leite. De posse dos dados objetivou-se verificar a aplicabilidade da Matriz Importância $x$ Desempenho como ferramenta para a priorização de ações de forma a ratificar o que fora constatado pela pesquisa.

\section{GESTÃO DE PROPRIEDADES RURAIS E SUSTENTABILIDADE AMBIENTAL}

A abertura comercial, a tão propalada globalização, trouxe a necessidade de profissionalizar a gestão das propriedades rurais, familiares ou não, como meio para melhorar a competitividade numa atividade que, por muito tempo, foi de subsistência. As exigências legais relativas aos agronegócios sofreram um incremento considerável, passando por adequações nas áreas da produção, da saúde e do meio ambiente. As constantes discussões sobre as questões ambientais tendem a estabelecer grupos específicos como responsáveis pelos problemas gerados pelo homem. Segundo Ribeiro, Brites e Junqueira 
(2006), dentre esses grupos, um dos que, muitas vezes, é citado como responsável pela progressiva deterioração do meio é o produtor rural.

\subsection{Administração de propriedades rurais}

Neste subitem, apresentam-se, de maneira sucinta, conceitos de gestão, buscando uma relação direta com as "empresas rurais".

Os empreendimentos rurais possuem um papel importante no cenário econômico regional, necessitando crescer e desenvolver-se de forma sustentável, porém, a ineficiência na administração afeta, negativamente, o desempenho dos mesmos. É primordial para a cadeia produtiva a melhoria dos mecanismos de gestão, pois a não adoção de técnicas que possibilitem o monitoramento do desempenho da atividade pode implicar na "exclusão de uma parte significativa dos produtores, visto que o setor entrou na era da competitividade em uma economia globalizada" (SOUZA, 2011, p.12).

Bortolini (2010) afirma que, nesse contexto de globalização, é preciso que os produtores rurais tenham a capacidade de ler e interpretar as exigências do ambiente interno e externo à propriedade. Para isso, será preciso desenvolver capacidades de gerenciamento cada vez mais profissionais. O autor ainda afirma que gerenciar uma propriedade rural familiar requer habilidades que, muitas vezes, o agricultor não está acostumado a praticar ou ainda não desenvolveu.

De acordo com França (2006), grande parte dos modernos conceitos de produção foram criados para os ditos "países desenvolvidos" em virtude das preocupações ambientais, sociais e econômicas distintas das condições brasileiras, o que determina que se busque a adaptação dos mesmos às particularidades de nosso país, principalmente, no que diz respeito à "diversidade existente no setor, tornando impossível aplicar ferramentas de gestão uniformemente em todas as propriedades" (BORTOLINI, 2010, p.9).

É importante levantar indicadores que possam ser utilizados como parâmetros para medir o desenvolvimento econômico, social e ambiental de propriedades rurais. Souza (2011, p.46) deixa claro que "o uso de métodos de gestão de propriedades familiares favorece a inserção nos mercados" o que leva a uma sustentabilidade econômica das propriedades e das famílias dos produtores de leite. 
Importante perceber que as propriedades produtoras de leite nada mais são do que empresas rurais e, como tal, é necessário considerar a necessidade de gestão das mesmas, pois empresa rural é aquela que explora a capacidade produtiva do solo por meio do cultivo da terra, da criação de animais e da transformação de determinados produtos agrícolas. Já administração rural é tida como sendo o conjunto de atividades que facilitam a tomada de decisão por parte dos produtores rurais restritas à sua propriedade, buscando obter o melhor resultado econômico e mantendo a produtividade da terra.

Para que se possa melhorar a capacidade de gerenciamento dessas empresas, faz-se necessário treinamento e capacitação tecnológica e gerencial dos produtores, pois a escolaridade, geralmente baixa, e a falta de habilidade gerencial é uma constante.

Nesse contexto Eyerkaufer (2007, p. 25) afirma que para administrar a atividade leiteira, é requerido conhecimento e informação que vão "além da memória do produtor". É preciso o uso de ferramentas gerenciais que garantam a sobrevivência da propriedade.

Administrar inclui as funções de planejamento, organização, direção e controle. Quando se fala de um empreendimento rural, é preciso considerar as suas particularidades que influem diretamente nestas funções, tais como: a dependência do clima; o tempo de produção (invariavelmente, maior do que o tempo de trabalho); a perecebibilidade dos produtos; a presença da terra como fator de produção; a estacionalidade da produção; a realização do trabalho de forma dispersa e ao ar livre; entre outras. Tomando isso por base, é preciso que o administrador rural, neste caso os próprios produtores rurais, sejam capazes de atuar de forma a minorar os efeitos advindos dessas particularidades.

Uma das características das empresas rurais familiares é o desenvolvimento de diferentes atividades concomitantemente ao leite e, neste sentido, os produtores "enfrentam dificuldades de identificar o resultado individual de cada atividade" (COSTA, 2010; p. 15). Para mitigar essa dificuldade, torna-se importante desenvolver um sistema de indicadores que permita verificar, entre as atividades desenvolvidas, qual é a mais rentável e merece maior atenção por parte do produtor. Sabendo qual a atividade mais rentável, de acordo com o mesmo autor, e para garantir a sustentabilidade, os produtores devem buscar e adotar 
novas tecnologias, como sistemas de gerenciamento, priorizar a atualização das informações e adotar mecanismos de aprendizagem e de formação profissional.

No processo de gestão de uma empresa, seja ela rural ou não, se pressupõe-se a presença de ações em diferentes áreas, tais como: gestão da produção, de pessoas, de marketing, de finanças, de custos, da logística, ambiental (foco deste trabalho), entre outras. De modo geral, os aspectos relacionados com a gestão que devem ser acompanhados incluem itens como a produtividade por animal, o consumo de leite pela família, o consumo de ração e outros insumos na alimentação, os custos com mão de obra terceirizada e familiar, as receitas oriundas da venda de leite e das demais atividades de forma individualizada, os custos relativos à estrutura necessária para a operação da atividade, entre outros.

É preciso que as estratégias de comercialização sejam traçadas com base no conhecimento dos mercados, dos canais de distribuição e das tendências. De outro lado, é preciso estar atento para identificar possíveis oportunidades que porventura surjam nos mercados dinâmicos no qual as empresas rurais estão inseridas.

\subsection{Sustentabilidade Ambiental}

A questão ambiental tem crescido de importância em todos os ramos da atividade econômica, na produção de leite não é diferente, tem-se de buscar um status e uma performance que permita a continuidade da atividade de forma sustentável.

Costa (2010) considera o desenvolvimento sustentável como algo que se pode considerar para além do crescimento econômico de uma empresa. Deve estar amparado na ideia de avaliar e pensar as formas de apropriação do meio pelo homem, sendo que a avaliação deve ser baseada em indicadores.

Para Albé (2002), a metodologia a ser utilizada para definição de quais indicadores são importantes para a sustentabilidade deve considerar o ambiente, além de avaliar a realidade em questão. Assim sendo, quando um conjunto de indicadores é estabelecido, é essencial que estes privilegiem as interações entre os componentes e suas dimensões, refletindo o sistema na sua forma mais global, sem 
desconsiderar as partes, portanto, devem privilegiar uma abordagem sistêmica.

A sustentabilidade dos pequenos produtores, para Altieri (1998), deve mostrar um indicador que estabeleça no mínimo quatro critérios, independentemente do método utilizado para avaliar essa sustentabilidade, a saber: manutenção da capacidade produtiva do agroecossistema; conservação dos recursos naturais e da biodiversidade; fortalecimento da organização social e, como consequência, diminuição da pobreza; fortalecimento das comunidades locais, preservando suas tradições, seu conhecimento e garantindo sua participação no processo de desenvolvimento.

As dificuldades de estabelecerem-se indicadores de sustentabilidade, para Albé (2002), advêm da falta de um consenso no conceito de desenvolvimento sustentável e nos objetivos a serem atingidos para chegar-se à sustentabilidade, pois, para realidades diferentes, existem respostas diferentes.

Há diferentes fatores que levam uma empresa, propriedade rural, a buscar a gestão ambiental, entre os quais se destacam quatro, quais sejam: a necessidade de reduzir custos, a necessidade de atender à legislação vigente, a possibilidade de melhorar a imagem da empresa e a necessidade de fornecer produtos, no caso das propriedades, insumos mais saudáveis e de melhor qualidade, o que Porter (1999) denominava como verde e competitivo. É preciso traçar estratégias que permitam reduzir o custo socioambiental decorrente da atividade leiteira.

Considerando a produção de leite, é possível afirmar que os produtores rurais terão, nessa área, um desafio a ser superado, pois será preciso encontrar formas de aumentar a rentabilidade dos empreendimentos com sustentabilidade ambiental. Isso requererá um processo de gestão que permita a continuidade das atividades de produção com um método menos agressivos ao meio ambiente. Como diria Baroni (2008), será preciso que os produtores rurais entendam que sustentabilidade e competitividade são conceitos complementares e que não há como atingir a segunda sem preocupar-se com a primeira.

A produção leiteira apresenta uma complexidade em seu processo, pois envolve o uso de água, animais, plantas, homens, terra, entre outros fatores. O uso desses recursos de forma equilibrada é 
condição que contribui, embora não exclusivamente, para alcançar a competitividade do negócio.

Verona (2008) considera que o conceito de sustentabilidade está sempre relacionado com a manutenção dos recursos naturais. Já Nolasco (1999) diz que, para avaliação da sustentabilidade de um agroecossistema, tem-se de considerar que os indicadores básicos podem ser produtividade, estabilidade, conservação de água, capacidade do sistema de resistir a pragas e doenças, ciclagem de carbono, diversidade cultural, recursos externos e capacidade de produzir receita.

O Vale do Taquari situa-se na Região Centro-Oeste do Rio Grande do Sul, sendo constituído por 36 municípios. No que diz respeito à agricultura, caracteriza-se pela produção em pequenas propriedades. Os estabelecimentos agrícolas estão concentrados no grupo de área com menos de 100 hectares, apresentando um elevado percentual de estabelecimentos em áreas inferiores a dez hectares.

A produção primária do Vale do Taquari está, intimamente, ligada ao processo de transformação agroindustrial, sendo beneficiados nas empresas privadas ou cooperativas agroindustriais da própria região. Dentre as diversas agroindústrias processadoras de produtos primários produzidos na região, merece destaque a agroindústria de lacticínios. Esse setor agroindustrial é composto por várias indústrias privadas e por duas grandes cooperativas

Além do processamento simples de pasteurização e embalagem do leite in natura para consumo, esse setor agroindustrial é responsável pela produção de vários derivados, que exigem o emprego de tecnologias e recursos humanos mais qualificados, destacando-se o leite em pó.

Também são produzidos queijos, manteiga, iogurte e outros derivados. A produção é vendida para os centros urbanos do Estado do RS e de outros estados do país, inclusive, para o mercado externo.

\subsection{A produção de leite no Vale do Taquari}

Segundo Rempel et al. (2012), os 36 municípios da região do Vale do Taquari apresentavam, em 2006, segundo dados do IBGE, 23.345 estabelecimentos agropecuários, contando com um rebanho bovino de 
241.527 cabeças, sendo 95.859 vacas de ordenha. O expressivo rebanho de vacas de ordenha resultou em uma produção de 286.620.000 litros de leite no ano de 2008. A referida produção leiteira representa a base da economia da maioria das pequenas propriedades rurais dos municípios do Vale do Taquari, indicando a importância desse sistema de produção.

Para Rempel et al. (2012) a ausência de práticas ambientais adequadas de manejo nas propriedades rurais e na própria atividade leiteira, principalmente, com relação aos dejetos bovinos, resulta em expressivos impactos ambientais, notadamente, sobre a baixa qualidade da água dos recursos hídricos superficiais da região. Não é o caso de, como concluem Ribeiro, Brites e Junqueira (2006), colocar o produtor rural na condição de réu, mas, sim, na condição de peça-chave de um processo, merecendo especial atenção e maiores cuidados, cabendo-lhe a responsabilidade de execução da prática das ações na justa proporção dos meios e condições que lhe forem disponibilizados.

Ao mesmo tempo, as organizações, sejam elas empresas ou pequenas propriedades rurais, de acordo com o apresentado por Cyrne e Santos (2003), devem buscar formas de incrementar a competitividade, identificar aspectos que permitam ganhar os pedidos em vez de somente qualificar-se a competir por eles. A competitividade de uma organização dá-se em função da sua capacidade de fazer o que os clientes valorizam e, sem dúvida, o aspecto ambiental torna-se cada vez mais um ganhador de pedidos.

Tendo em vista ações legais que vêm sendo desenvolvidas com a finalidade de obrigar os proprietários a ajustarem as suas propriedades às exigências ambientais, a intervenção na gestão buscando minorar o impacto dos procedimentos de produção, torna-se de grande importância. Porém, é preciso entender que um sistema de produção ambientalmente correto deve ultrapassar o simples atendimento das exigências legais, como diria Albé (2002), está associada à colocação dos produtos no mercado, o que gera reflexos no desempenho e manutenção das propriedades, principalmente, as pequenas e médias. Para tanto, será necessário que as propriedades sejam capazes de adequar sua forma de atuar e de se relacionar com as questões ambientais. 
Diante desse quadro, Rempel et al. (2012) realizaram uma pesquisa baseada nas propostas de Verona (2008) e em Rodrigues e Campanhola (2003), com o intuito de elaborar uma metodologia de análise ambiental que gerasse um índice de qualidade ambiental das propriedades produtoras de leite, contribuindo, assim, para o diagnóstico ambiental do sistema de produção leiteiro da região do Vale do Taquari, buscando os pontos positivos e negativos das práticas em vigor e capacitar os produtores rurais a gerenciar a referida atividade e as práticas agrícolas consorciadas de forma sustentável. Ou seja, manter ou mesmo elevar o retorno econômico, mas com a execução de práticas que favoreçam a preservação dos elementos naturais das propriedades rurais.

\section{PROCEDIMENTOS METODOLÓGICOS}

A proposta metodológica foi proposta e aplicada em quatro propriedades produtoras de leite no Município de Arroio do Meio-RS, que é o terceiro maior produtor de leite do Vale do Taquari (REMPEL et al., 2012). A pesquisa teve início no ano de 2010, com agendamento de reuniões com a Secretária de Agricultura e a Empresa de Assistência Técnica e Extensão Rural - EMATER, visto que ambas as instituições manifestaram interesse no desenvolvimento de ações com os produtores de leite.

Ato contínuo, realizou-se uma reunião com os produtores do município, na localidade de Linha 32 , onde os objetivos do projeto foram apresentados, sendo que quatro produtores manifestaram, voluntariamente, o desejo de participar do projeto.

$\mathrm{Na}$ continuidade, coletaram-se os dados a campo. De posse desses resultados, passou-se a buscar a possibilidade de analisar as mesmas variáveis sob a ótica da Matriz Importância $x$ Desempenho, adaptada de Slack (2002) de nove pontos. Para tanto, foi necessária a adaptação da matriz que, originalmente, apresenta como de maior importância, ou de melhor desempenho, a variável assinalada com valor mais próximo de um e de menor importância, ou pior desempenho, a com indicação mais próxima de nove. Porém, para viabilizar a utilização da matriz, realizou-se a inversão desses valores, sendo então, os 
valores menores referentes à menor importância ou desempenho e os valores maiores referentes à maior importância ou desempenho.

Para a consecução dos objetivos propostos, Rempel et al. (2012) valeram-se dos passos constantes da Figura 2. 
Figura 2. Etapas da pesquisa

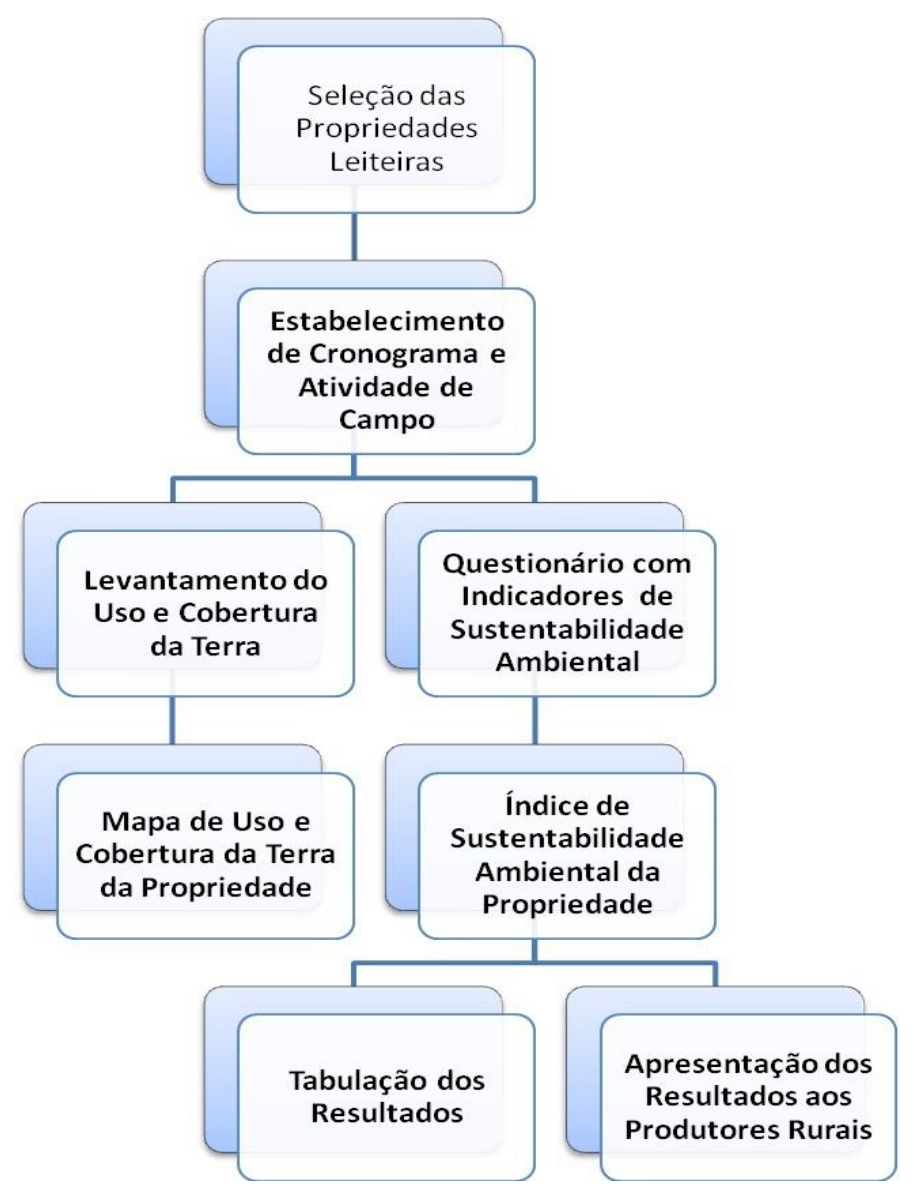

Fonte: Rempel et al. (2012).

\subsection{A matriz importância $x$ desempenho}

A matriz importância $\mathrm{x}$ desempenho, desenvolvida por Slack (2002), é uma ferramenta que permite priorizar as ações das empresas com base na importância das variáveis para as partes interessadas e no desempenho demonstrado pela organização. É composta de quatro "zonas" distintas a seguir descritas:

a) "zona de excesso", o desempenho da propriedade para determinado indicador ambiental pode ser considerado para além do necessário, porém, não para além do desejado, não podendo, assim, ser considerado um desperdício. Isso pode significar, porém não obrigatoriamente, que a propriedade esteja despendendo recursos em suas operações que não obrigatoriamente são reconhecidos pelos clientes. Slack (2002, p. 205) afirma que "é sensato checar para ver se algum recurso 
usado para atingir esse desempenho pode ser desviado para uma área mais necessitada";

b) $\mathrm{Na}$ "zona apropriada", o desempenho da propriedade para determinada dimensão competitiva estará satisfatório dentro dos critérios de importância estabelecidos pelo cliente para essa mesma dimensão. $O$ indicador ambiental que cair nessa zona é considerado satisfatório, pelo menos, no curto e no médio prazo. Como essa zona é limitada em sua margem inferior pela fronteira do "limite mínimo de desempenho" (SLACK, 2002; p.204), a propriedade deve estar sempre preocupada em não permitir que seu desempenho desça abaixo desse limite. Na verdade, o objetivo de longo prazo deve mover seu desempenho para o mais próximo possível do limite superior desta zona, porque é grande a importância dada pelo cliente para uma determinada dimensão competitiva;

c) $\mathrm{Na}$ "zona de melhoramento", o desempenho da propriedade para determinado indicador ambiental estará um pouco aquém dos critérios de importância estabelecidos pelo cliente para essa mesma dimensão. Como essa zona se encontra abaixo da fronteira do "limite de desempenho", cabe à propriedade avaliar as prioridades de melhoria, no intuito de adequar seu nível de desempenho à importância dada pelo cliente;

d) $\mathrm{Na}$ "zona de ação urgente", o desempenho da propriedade para um indicador ambiental abaixo dos critérios de importância estabelecidos pelo cliente para essa mesma dimensão, ou seja, a propriedade está entregando para o cliente algo aquém daquilo que ele espera. Essa zona sinaliza que a propriedade deve rever suas operações com o objetivo de se adequar às expectativas do cliente. SLACK (2002, p.205) menciona que

os objetivos de curto prazo, portanto, devem ser melhorar o desempenho de qualquer objetivo de desempenho que caia nesta zona, pelo menos até a zona de melhoria, enquanto no médio prazo eles precisam ser trabalhados para cima e além do limite inferior da zona apropriada. 
Assim como as zonas acima descritas possuem elevada importância no estudo da matriz Importância x Desempenho, alguns tipos de movimentação dentro da matriz também são de grande relevância. O movimento ascendente tem como principal objetivo melhorar o desempenho da propriedade em relação à concorrência (e por que não dizer em relação ao seu próprio desempenho), no ponto em que se pode imaginar uma movimentação da produção ou das operações da empresa.

Neste trabalho, buscou-se realizar o enquadramento dos resultados encontrados por Rempel et al. (2012) na matriz Importância x Desempenho. A primeira escala - de "importância" - foi adaptada a partir dos pesos atribuídos aos diferentes indicadores constantes da Tabela 1, sendo que 'dejetos' foi tomado como de maior importância (nove pontos), tendo em vista ser o item de maior peso dentro do índice de sustentabilidade ambiental. Para os demais itens, calculou-se a proporção entre o peso de cada item em relação ao item 'dejetos', que foi tomado como 100\%. Assim, o item 'uso da terra' passou a ser o menos importante, $2 \%$ (0,6 pontos).

A Figura 3 mostra, de maneira adaptada, a matriz Importância $x$ Desempenho. Há quatro áreas que são as chamadas zonas: de excesso, apropriada, de melhoramento e de ação urgente.

Figura 3. Matriz Importância x Desempenho

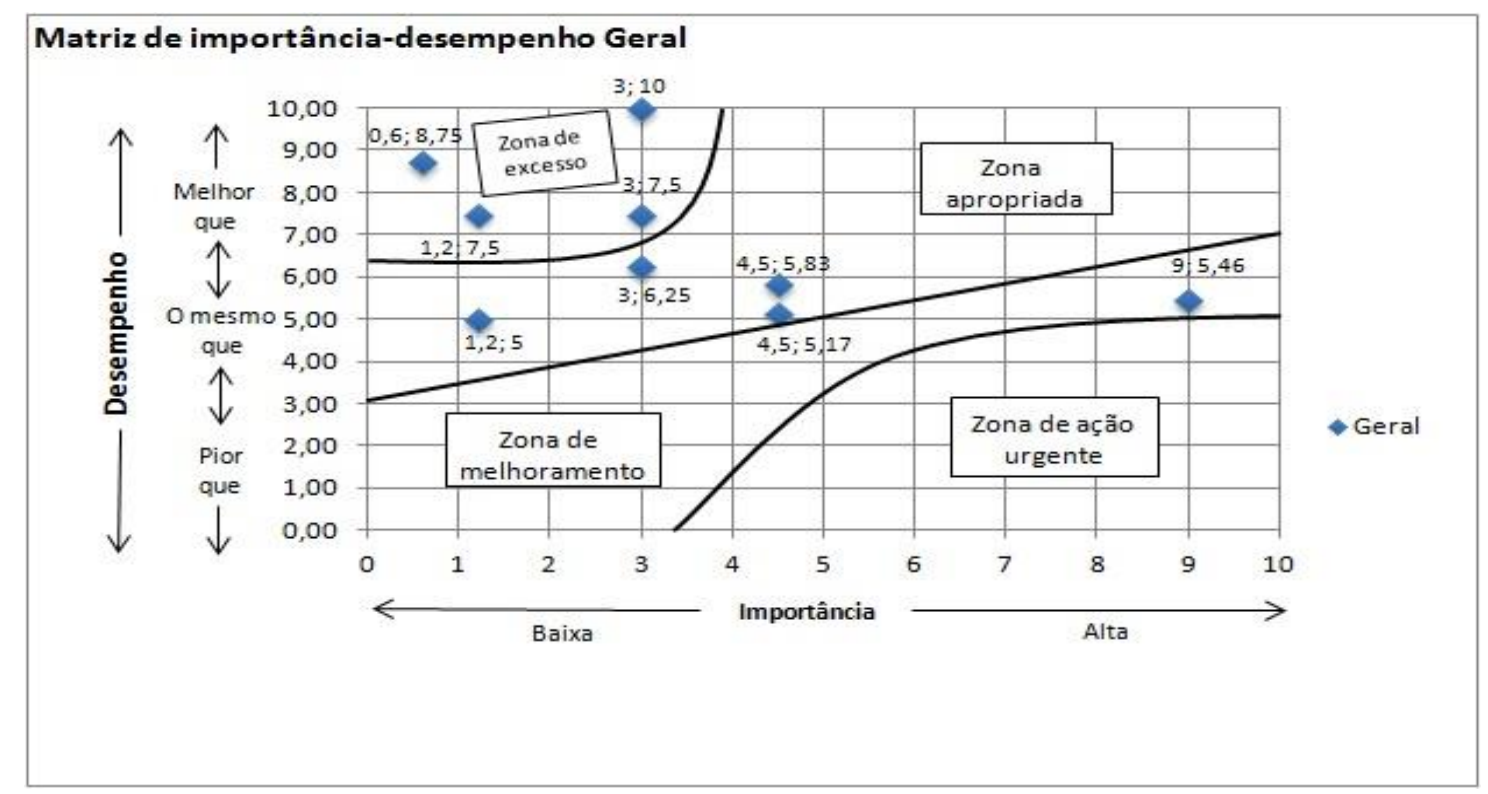

Fonte: Elaborado pelos autores adaptado de Slack, 2002. 


\section{RESULTADOS E DISCUSSÕES}

Ao aplicar a metodologia de avaliação da sustentabilidade ambiental, nas propriedades participantes da pesquisa desenvolvida por Rempel et al. (2012), foi possível verificar que são necessárias etapas interdependentes e que se sucedem de forma cronológica para a sua efetivação.

A avaliação da sustentabilidade ambiental das propriedades estudadas foi realizada com base em nove parâmetros: dejetos, água, Área de Preservação Permanente - APP, reserva legal, agrotóxicos e fertilizantes, declividade do terreno, erosão, queimadas e diversidade de usos da terra.

Alguns desses nove parâmetros estão subdivididos em subparâmetros (Quadro 1), totalizando 13 subparâmetros. Com base nessa metodologia, a pontuação máxima de uma propriedade leiteira com sustentabilidade ambiental equivale a 100 pontos, sendo os dejetos produzidos na produção leiteira considerado o indicador mais importante. 
Quadro 1. Parâmetros, subparâmetros e pontuação de avaliação da sustentabilidade ambiental

\begin{tabular}{|l|c|l|c|}
\hline \multicolumn{1}{|c|}{ Parâmetro } & $\begin{array}{c}\text { Pontuaçã } \\
\text { Dejetos }\end{array}$ & \multicolumn{1}{|c|}{ Subparâmetro } & $\begin{array}{c}\text { Pontuaçã } \\
0\end{array}$ \\
\hline & & Armazenamento do dejeto sólido & 10 \\
\hline APP* & 15 & Armazenamento do dejeto líquido & 10 \\
\hline Agestinação do dejeto animal & Percentual de utilização das APPs & 10 \\
\hline $\begin{array}{l}\text { e } \\
\text { Fertilizantes }\end{array}$ & 15 & $\begin{array}{l}\text { Utilização de Fertilizantes químicos e } \\
\text { agrotóxicos }\end{array}$ & 10 \\
\hline & & $\begin{array}{l}\text { Armazenamento de embalagens de } \\
\text { agrotóxicos }\end{array}$ & 5 \\
\hline $\begin{array}{l}\text { Reserva } \\
\text { Legal* }\end{array}$ & 10 & $\begin{array}{l}\text { Percentual de vegetação nativa para } \\
\text { averbação em reserva legal }\end{array}$ & 10 \\
\hline Água & 10 & Fonte de água & 10 \\
\hline Declividade* & 10 & Declividade do terreno & 10 \\
\hline Erosão & 4 & Evidências de solo erodido & 4 \\
\hline Queimadas & 4 & Evidências de queimadas & 4 \\
\hline Usos de terra & 2 & Diversidade de coberturas & 2 \\
\hline Totais & - & - & 100 \\
\hline
\end{tabular}

Fonte: Rempel et al., 2012.

A atribuição da pontuação dentro de cada subparâmetro foi realizada considerando a melhor situação (maior pontuação), reduzindo na direção da pior situação (menor pontuação), com valores intermediários de acordo com o risco ou exposição ao impacto ambiental. O quadro 2 apresenta as situações possíveis de serem identificadas em campo para os subparâmetros e a respectiva pontuação.

Por meio das propriedades analisadas, pode-se verificar que os índices de sustentabilidade ambiental, atribuídos por meio da presente proposta metodológica, representam o nível de adequação de cada indicador em percentual em cada propriedade leiteira, conforme pode ser observado no quadro 2, sendo os destacados, em negrito, aqueles que se constituem nos principais aspectos-alvo de intervenção para adequação. 
Quadro 2. Nível de adequação dos indicadores ambientais nas quatro propriedades leiteiras analisadas

\begin{tabular}{|l|c|c|c|c|c|}
\hline \multicolumn{1}{|c|}{$\begin{array}{c}\text { Indicador } \\
\text { Ambiental }\end{array}$} & $\begin{array}{c}\text { Propriedade } \\
\text { A }\end{array}$ & $\begin{array}{c}\text { Propriedade } \\
\text { B }\end{array}$ & $\begin{array}{c}\text { Propriedade } \\
\text { C }\end{array}$ & $\begin{array}{c}\text { Propriedad } \\
\text { e D }\end{array}$ & Média \\
\hline Dejetos & 43,33 & $\mathbf{2 6 , 6 7}$ & 56,67 & 91,67 & 54,58 \\
\hline Água & 75,00 & 100,00 & 50,00 & 75,00 & 75,00 \\
\hline APP & 6,67 & 56,67 & 70,00 & 100,00 & 58,33 \\
\hline Reserva Legal & 100,00 & 100,00 & 100,00 & 100,00 & 100,00 \\
\hline $\begin{array}{l}\text { Agrotóxicos e } \\
\text { fertilizantes }\end{array}$ & 43,33 & 43,33 & 43,33 & 76,67 & 51,66 \\
\hline Declividade & 50,00 & 75,00 & 50,00 & 75,00 & 62,50 \\
\hline Erosão & 0,00 & 100,00 & 0,00 & 100,00 & 50,00 \\
\hline Queimadas & 100,00 & 100,00 & 100,00 & 0,00 & 75,00 \\
\hline Uso de terra & 100,00 & 100,00 & 100,00 & 50,00 & 87,50 \\
\hline $\begin{array}{c}\text { Índice de } \\
\text { Sustentabilidad } \\
\text { e Ambiental }\end{array}$ & 49,00 & 60,50 & 60,00 & 84,00 & 63,37 \\
\hline
\end{tabular}

Fonte: Rempel et al. (2012).

De posse dos resultados, passou-se à elaboração das matrizes importância $x$ desempenho. Para tanto, para que se pudesse utilizar a escala proposta realizou-se a normalização dos dados, dividindo-os por dez. Abaixo, a matriz referente a cada uma das propriedades que se passa a analisar (Figura 4).

Figura 4. Matriz Importância x Desempenho Propriedade A 


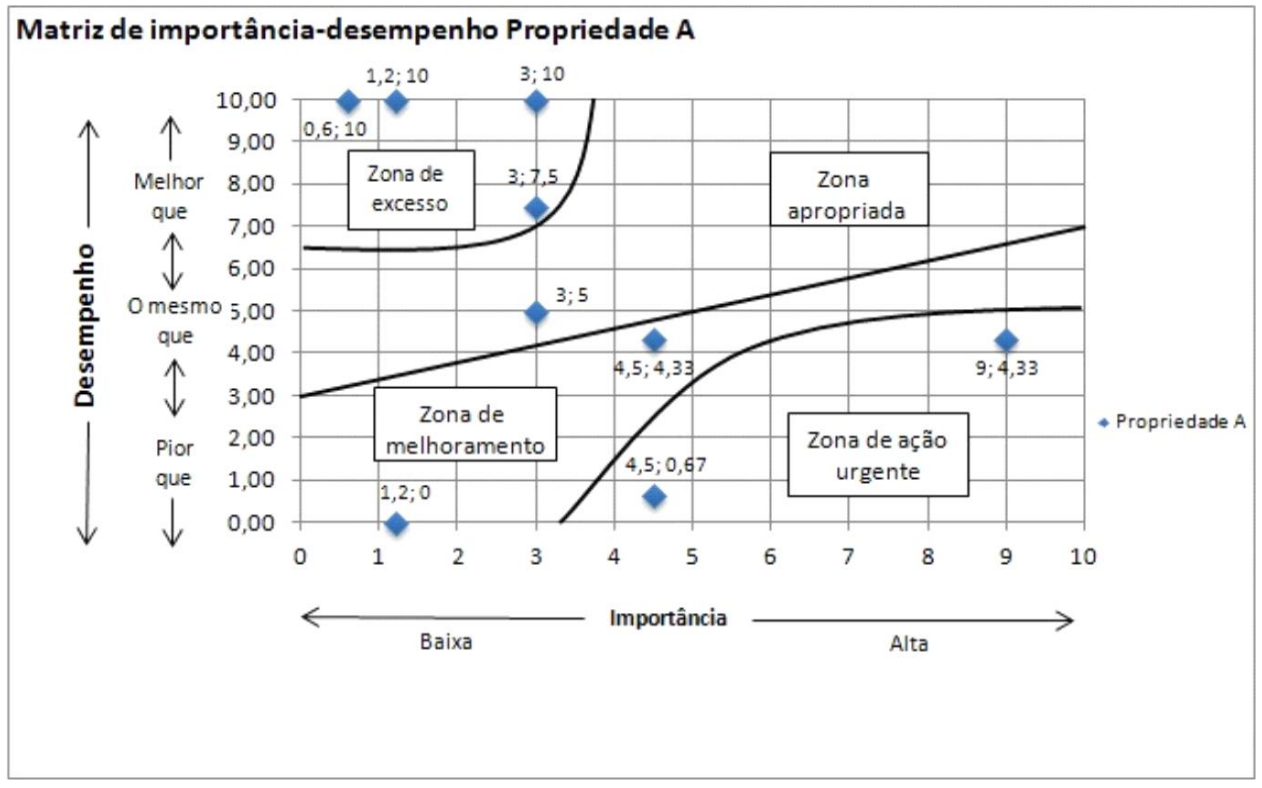

Fonte: elaborado pelos autores

É possível observar que dois pontos se encontram na zona de ação urgente, demonstrando a necessidade de intervenção imediata, sendo estes: APP e destinação de dejetos. Já na zona de melhoria, temos, também, dois pontos: erosão e agrotóxicos e fertilizantes. $\mathrm{Na}$ zona apropriada, temos somente um ponto: declividade.

Falar em excesso quando se está abordando questões ambientais é um contrassenso, portanto passar-se a utilizar a expressão "zona de excelência", por parecer mais adequada. Nessa zona, tem-se quatro pontos: reserva legal, queimadas, uso da terra e água. Na avaliação dos autores deste trabalho, o excesso é algo desejado e, portanto, deve ser perseguido, pois caracterizaria uma gestão de excelência em relação aos aspectos ambientais das propriedades.

Para a propriedade B, Figura 5 , é preciso considerar que a matriz apresenta um número menor de pontos, pois alguns desempenhos foram idênticos, levando a uma sobreposição de alguns deles quando da plotagem na matriz. Pode-se constatar um ponto na zona de ação urgente, destinação de dejetos, requerendo atenção imediata e um ponto, agrotóxicos e fertilizantes, na zona de melhoria. Veja-se que o item dejetos está presente na zona de urgência nas duas propriedades, mas o resultado mais preocupante encontra-se na propriedade $B$ com um desempenho de somente 2,667 pontos. Na zona apropriada, tem-se somente um ponto: APP. Quando se observa a zona de excelência tem- 
se o maior número de pontos (6): uso da terra, erosão, queimadas, reserva legal, declividade e uso da água.

Figura 5. Matriz Importância x Desempenho propriedade B

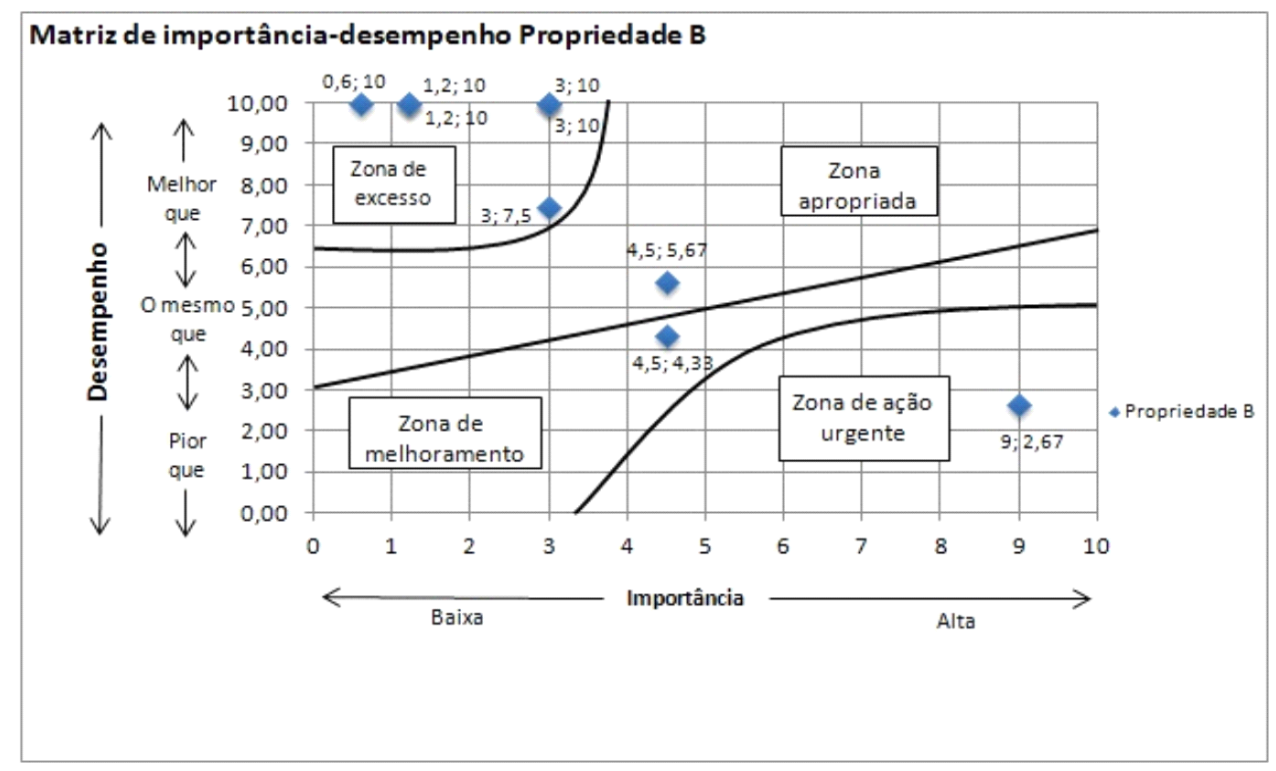

Fonte: elaborado pelos autores

A análise da propriedade C, Figura 6, traz como primeiro ponto positivo a inexistência de itens na zona de ação urgente. São três pontos: erosão, agrotóxicos e fertilizantes e dejetos na zona de melhoria. $O$ item dejetos demostra desempenho superior quando comparado com as propriedades anteriores. Na zona apropriada temos três pontos: declividade, uso da água e APP. Observando a zona de excelência, encontra-se, da mesma forma, três pontos: queimadas, uso da terra e reserva legal. Observe-se que a presença de três pontos em cada uma das zonas, exceto a zona de ação urgente onde não há itens, aponta para uma gestão equilibrada dos recursos. Porém, isso não pode induzir a uma possível acomodação por parte dos gestores da propriedade, pois entre os itens que merecem atenção na busca de melhoria temos a presença do item dejetos, considerado o mais importante. 
Figura 6. Matriz Importância x Desempenho propriedade C

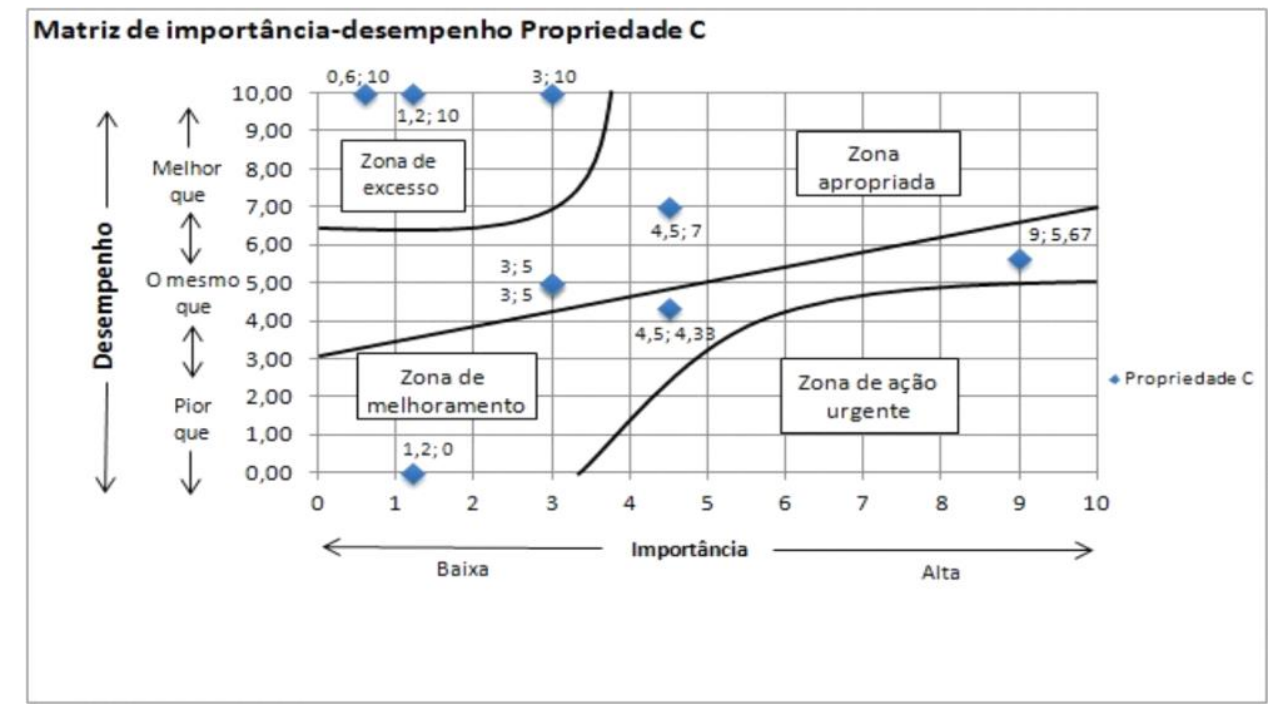

Fonte: elaborado pelos autores.

Para a propriedade D, Figura 7 , assim como na propriedade C, não há pontos que necessitem de intervenção imediata. Na zona de melhoria, tem-se, tão somente, um ponto: queimadas, estando nas zonas apropriada e de excesso a concentração dos pontos (4 em cada uma delas). Na zona apropriada, merece destaque o desempenho do item dejetos, que se apresenta como o melhor desempenho entre todas as propriedades. Os demais itens nessa zona são: agrotóxicos e fertilizantes, APP e uso da terra. Já na zona de excelência, tem-se: erosão, reserva legal, declividade e uso da água.

Figura 7. Matriz Importância x Desempenho propriedade D 


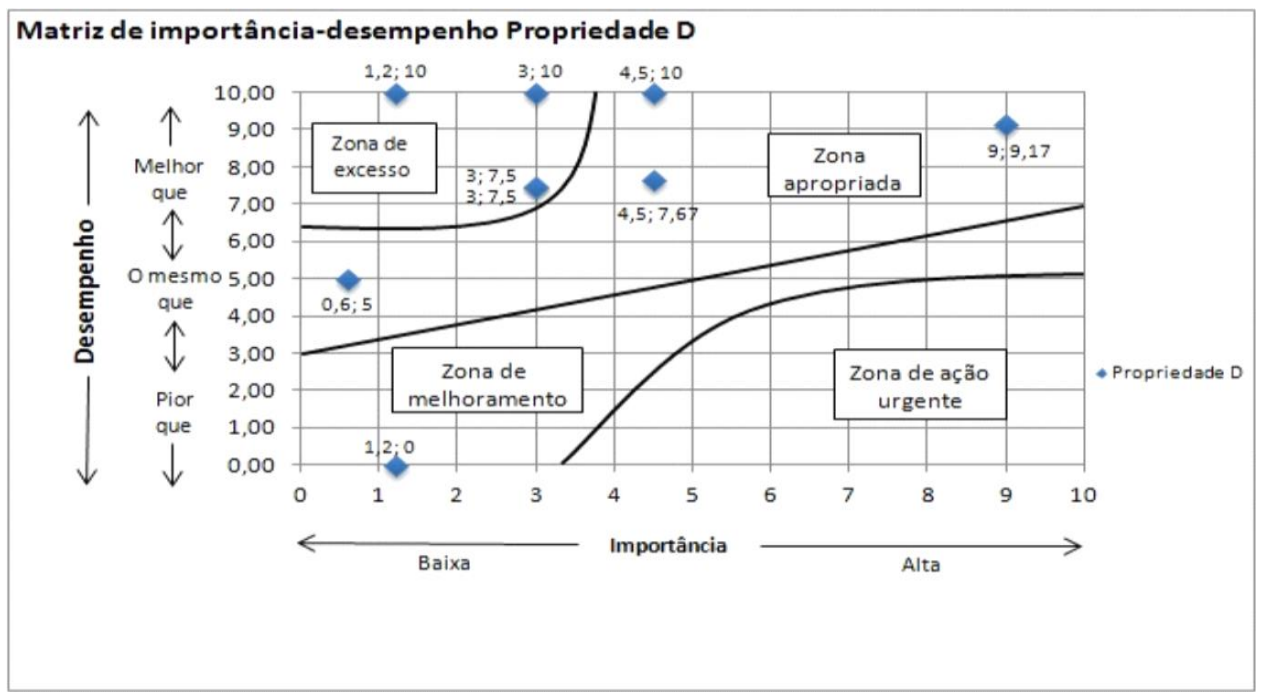

Fonte: elaborado pelos autores.

A partir dos dados, é possível verificar a diversidade de desempenhos. Os pontos presentes nas diferentes áreas da matriz se diferenciam, e em alguns casos de forma bastante discrepantes, como, por exemplo, o item dejetos que na propriedade $B$ tem um desempenho que coloca este ponto na zona de ação urgente, enquanto que, na propriedade $D$, este item apresenta um desempenho "quase" perfeito. Isso só confirma a afirmação trazida anteriormente, que apontava para a impossibilidade de adoção de técnicas e ferramentas de gestão uniformes para as propriedades rurais, necessitando de adaptação às particularidades de cada uma delas de forma a obter melhores resultados.

Fruto dessas diferenças, optou-se por criar uma matriz com os valores médios, mesmo sabendo que uma análise baseada somente na média é frágil, sendo desejável o uso de outras medidas de dispersão. $\mathrm{O}$ desempenho das propriedades, no seu conjunto, pode ser observado na Figura 8.

Figura 8. Matriz Importância x Desempenho Geral 


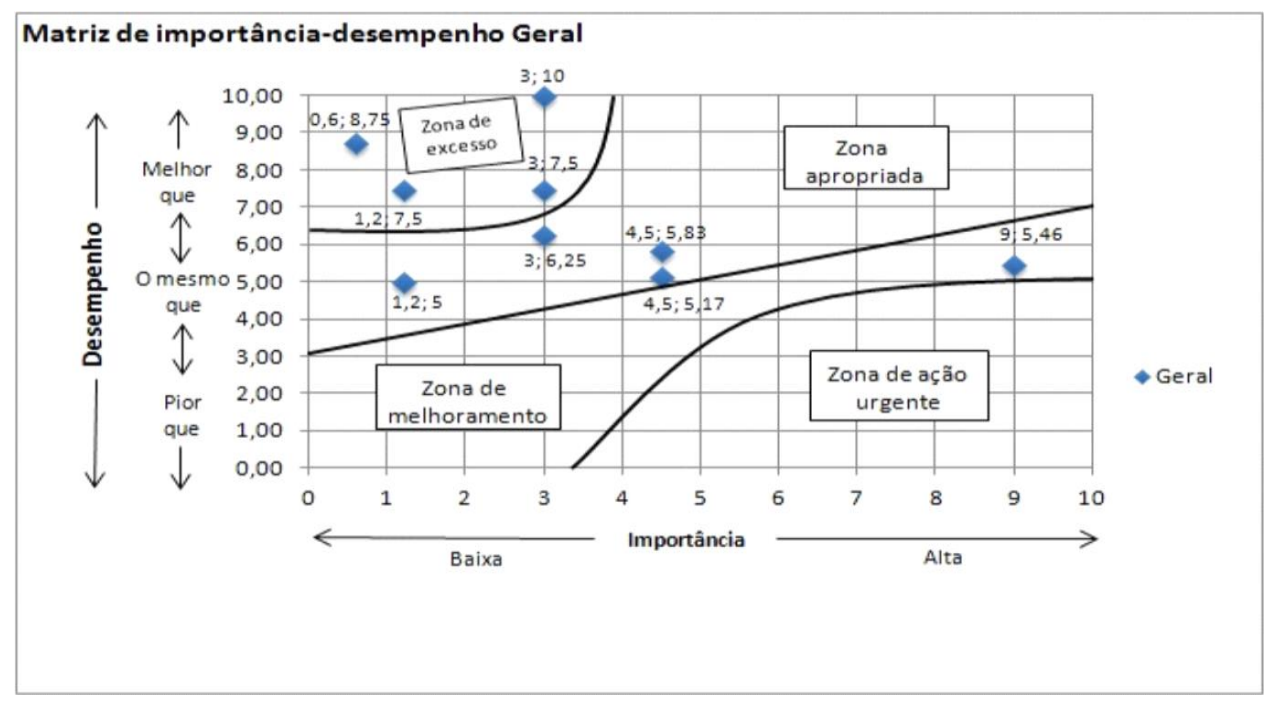

Fonte: elaborados pelos autores.

É importante destacar a não existência de pontos na zona de ação urgente, lembrando que se trata de médias, o que faz com que, mesmo existindo duas propriedades com itens nessa zona, o conjunto das propriedades tivesse melhor desempenho. Isso é confirmado pelo fato de que o item dejetos, que consta entre os itens que estão na zona de ação urgente nas propriedades A e B, tenha, no geral, sua posição modificada para a zona de melhoria. Na zona apropriada, tem-se quatro pontos: erosão, agrotóxicos e fertilizantes, APP e erosão. Na zona de excelência, estão presentes os pontos: uso da terra, queimadas, reserva legal e uso da água.

Os resultados apontam para a possibilidade do Município de Arroio do Meio tomar a propriedade $\mathrm{D}$ como modelo e propor políticas públicas que auxiliem as demais a alcançar desempenho semelhante. Tendo isso presente, pode-se passar para as conclusões.

\section{CONSIDERAÇÕES FINAIS}

O presente trabalho se propunha a verificar a aplicabilidade da matriz Importância x Desempenho como ferramenta de priorização de ações de forma a ratificar o que fora constatado pela pesquisa desenvolvida por Rempel et al. (2012), o que se mostrou viável. A matriz aponta para pontos presentes nas zonas de ação urgente e de melhoria que coincidem com os índices de menor valor apontados pela pesquisa. Assim, conclui-se que o uso da matriz Importância $x$ Desempenho pode 
ser uma ferramenta útil no processo de gestão ambiental das propriedades produtoras de leite no Município de Arroio do Meio e, muito provavelmente, em outras propriedades de outros municípios.

É preciso ter presente que estudos sobre a gestão das propriedades produtoras de leite podem auxiliar no desenvolvimento social, econômico e ambiental da região. Futuramente, podem ser desenvolvidos novos estudos aprofundando as questões ambientais e contemplando aspectos relacionados à gestão das propriedades rurais produtoras de leite.

\section{REFERÊNCIAS}

ALBÉ, Maristela de Quadros. Alguns Indicadores de Sustentabilidade para os Pequenos Médios Produtores Rurais do Município de Jaquirana. 2002. 129 f. Dissertação (Mestrado em Engenharia: Energia, Ambiente e Materiais) - Universidade Luterana do Brasil, Canoas. 2002.

ALTIERI, M.A. Agroecologia: a dinâmica produtiva da agricultura sustentável. Porto Alegre: Ed. UFRGS, 1998.

BARONI, S. A. Sustentabilidade do Negócio do Leite na Agricultura Familiar e o Desenvolvimento Regional. In: SANTOS, Geraldo Tadeu dos, et al. Bovinocultura de Leite: inovação tecnológica e sustentabilidade. Maringá: Eduem, 2008.

BORTOLINI, Gilberto. Gestão da Pequena Unidade Familiar Produtora de Leite: um modelo de gestão através da compreensão da unidade de produção. 2010. 57 f. Monografia (Especialização em Gestão do Agronegócio,) - Unisinos, São Leopoldo, 2010.

COSTA, Fábio Miguel Gonçalves da. Controles Gerenciais em Propriedades que Utilizam o Método de Pastoreio Racional Voisin (PRV) no Oeste de SC: um estudo exploratório. 2010. 85 f. Dissertação (Mestrado em Contabilidade do Setor de Ciências Sociais Aplicadas ) Universidade Federal do Paraná, 2010. 
CYRNE, Carlos C. da S. SANTOS, Carlos H. S. Cinco indicadores de desempenho e empresas certificadas ISO 9000 no Vale do Taquari. Lajeado: Univates, Estudo e Debate, Volume 10 n 1, 2003.

EYERKAUFER, Marino Luiz. Contabilidade Gerencial na Gestão de Propriedades Rurais: um estudo das propriedades leiteiras nos extremo oeste do estado de Santa Catarina. 2007. 151 f. Dissertação (Mestrado em Ciências Contábeis) - Universidade Regional de Blumenau , 2007.

FRANÇA, Silvia Resende de Albuquerque e. Perfil dos Produtores, Características das Propriedades e Qualidade do Leite Bovino nos Municípios de Esmeralda e Sete Lagoas - MG. 2006. 112 F. Tese (Doutorado em Ciência Animal) - Universidade Federal de Minas Gerais, Belo Horizonte, 2006.

INSTITUTO BRASILEIRO DE GEOGRAFIA E ESTATÍSTICA. Censo agropecuário. Rio de Janeiro: IBGE, 2006. Disponível em: <http://www.ibge.gov.br/cidadesat >. Acesso em: 10 nov. 2010.

INSTITUTO BRASILEIRO DE GEOGRAFIA E ESTATÍSTICA. Pesquisa da Pecuária Municipal. Rio de Janeiro: IBGE, 2011. Disponível em: <http://www.ibge.gov.br/cidadesat>. Acesso em: 18 mar. 2013.

MARION FILHO, Pascoal José; FAGUNDES, Jones de Oliveira; SCHUMACHER, Gabriela. A Produção de Leite no Rio Grande do Sul: produtividade, especialização e concentração (1990-2009). Revista de Economia e Agronegócios, Viçosa, v.9, n.2, maio/ago. 2011. Disponível em:

$<$ http://www.economiaaplicada.ufv.br/revista/pdf/2011/v9n2/Artigo\%204.pdf>. Acesso em 10 nov. 2010.

NOLASCO, Fábio. Avaliação da sustentabilidade em agroecossistemas: um método fitotécnico. 1999. 225 f. Tese ( Mestrado em Fitotecnia) Universidade Federal de Viçosa, Viçosa. 1999.

PORTER, Michael E. Competição - On Competition: estratégias competitivas essenciais. Rio de Janeiro: 1999. 
REMPEL, Claudete et al. Proposta Metodológica de Avaliação da Sustentabilidade Ambiental de Propriedades Produtoras de Leite. Revista Tecno-Lógica, Santa Cruz do Sul, v.16, n.1, 2012. Disponível em <http://www.http://online.unisc.br/seer/index.php/tecnologica/article /view/2613/2094>. Acesso em 18 mar. 2013.

RIBEIRO, Antonio C. F.; BRITES, Ricardo S.; JUNQUEIRA, Ana M. R.. Os aspectos ambientais no processo decisório do produtor rural: estudo de caso Núcleo Rural Taquara. Revista brasileira de engenharia agrícola e ambiental. Campina Grande, v. 10, n. 3, set. 2006 . Disponível em $<$ http: / www.scielo.br/scielo.php?script $=$ sci_arttext\&pid $=$ S1 $415-$ $43662006000300022 \&$ lng $=$ pt\&nrm=iso $>$. Acesso em 16 jan. 2011. $<$ http://dx.doi.org/10.1590/S1415-43662006000300022>.

RIO GRANDE DO SUL. Secretaria de Desenvolvimento e Promoção do Investimento. Plano de Implantação da Política Industrial Desenvolvimento Econômico do RS. Porto Alegre, SDPI: [entre 2010 e 2013] Disponível em: <http://www.sdpi.gov.br> Acesso em: 10 mai. 2013.

RODRIGUES, Geraldo Stachetti; CAMPANHOLA, Clayton. Sistema integrado de avaliação de impacto ambiental aplicado a atividades do Novo Rural. Pesquisa Agropecuária Brasileira, Brasília, v. 38, n. 4, p. 445-451, abr. 2003.

SILVA NETO, Benedito; BASSO, David. A Produção de Leite como Estratégia de Desenvolvimento para o Rio Grande do Sul. Desenvolvimento em Questão. Editora Unijuí, v. 3, n.5, jan./jun. 2005.

SLACK, Nigel. Vantagem Competitiva em Manufatura: atingindo a competitividade nas operações industriais. São Paulo: Atlas, 2002.

SOUZA, R. M. H. A Influência do Ambiente Institucional e Organizacional no Desenvolvimento Rural de Propriedades Produtoras de Leite na Região Extremo-Oeste Catarinense. 2011.125 p. Dissertação (Mestrado 
em Desenvolvimento Regional e Agronegócios) - Universidade Estadual do Oeste do Paraná, Toledo, 2011.

VERONA, Luís Augusto Ferreira. Avaliação de sustentabilidade em agroecossistemas de base familiar e em transição agroecológica na região sul do Rio Grande do Sul. 2008. 193 f. Tese (Doutorado em Ciências: Produção Vegetal) - Universidade Federal de Pelotas, Pelotas. 2008.

Submetido em 28/06/2013

Aprovado em 30/03/2015

Sobre os autores

\section{Carlos Candido da Silva Cyrne}

Programa de Pós-graduação em Ambiente e Desenvolvimento, Centro Universitário UNIVATES.

E-mail: cyrne@univates.br

\section{Claudete Rempel}

Programa de Pós-graduação em Ambiente e Desenvolvimento, Centro Universitário UNIVATES.

E-mail: crempel@univates.br

\section{Claus Haetinger}

Programa de Pós-graduação em Ambiente e Desenvolvimento, Centro Universitário UNIVATES.

E-mail: chaet@univates.br

Rafael Rodrigo Eckhardt

Curso de Engenharia Ambiental, Centro Universitário UNIVATES.

E-mail: rafare@univates.br 